\title{
Entamoeba histolytica: Gene Expression Analysis of Cells Invading Tissues
}

\author{
Helen C. Fernandes, ${ }^{1}$ Ana F. Costa, ${ }^{1}$ Michelle A. R. Freitas, ${ }^{2}$ Almir S. Martins, ${ }^{3}$ \\ Jorge L. Pesquero, ${ }^{3}$ Élida M. Rabelo, ${ }^{1}$ and Maria A. Gomes ${ }^{1}$ \\ ${ }^{1}$ Department of Parasitology, Institute of Biological Sciences, Universidade Federal de Minas Gerais, \\ 31270-901 Belo Horizonte, MG, Brazil \\ ${ }^{2}$ Laboratory of Parasitology, Institute of Biomedical Sciences, Universidade Federal de Uberlândia, \\ 38400-902 Uberlândia, MG, Brazil \\ ${ }^{3}$ Department of Physiology and Biophysics, Institute of Biological Sciences, Universidade Federal de Minas Gerais, \\ 31270-901 Belo Horizonte, MG, Brazil
}

Correspondence should be addressed to Maria A. Gomes; magomes@icb.ufmg.br

Received 5 August 2013; Accepted 5 December 2013; Published 27 January 2014

Academic Editors: M. Chenik and M. J. Perteguer

Copyright ( 2014 Helen C. Fernandes et al. This is an open access article distributed under the Creative Commons Attribution License, which permits unrestricted use, distribution, and reproduction in any medium, provided the original work is properly cited.

Entamoeba histolytica is a protozoan parasite that presents a risk to the health of millions of people worldwide. Due to the existence of different clinical forms caused by the parasite and also different virulence levels presented by one strain, one would expect differences in the profile of gene transcripts between virulent and nonvirulent cultures. In this study we used the differential display to select gene segments related to invasiveness of amoeba. One Brazilian strain of E. histolytica in two conditions, able or not to cause lesions in experimental animals, was used. RNA from this strain, was used to study the differential expression of genes. 29 specific gene fragments differentially expressed in the virulent strain were selected. By real-time PCR, six of these genes had confirmed their differential expression in the virulent culture. These genes may have important roles in triggering invasive amoebiasis and may be related to adaptation of trophozoites to difficulties encountered during colonization of the intestinal epithelium and liver tissue. Future studies with these genes may elucidate its actual role in tissue invasion by E. histolytica generating new pathways for diagnosis and treatment of amoebiasis.

\section{Introduction}

Entamoeba histolytica, the protozoan responsible for amoebiasis, a disease that affects millions of people worldwide $[1,2]$, presents great diversity of clinical manifestations ranging from asymptomatic intestinal infections to intestinal and extra-intestinal invasion. It is speculated that the result of the infection constitutes a multifactorial event mainly determined by two factors: the potential pathogenic of $E$. histolytica strain and the host immune response [3]. Among factors related to the parasite, the profile of gene transcription has been extensively studied. Biochemical and molecular differences between virulent and nonvirulent strains have been described [4]. Recent research pointed to increased gene expression of molecules related to tissue lysis, phagocytosis, and motility in invasive amoebas. Among these are poreforming proteins, phospholipase $\mathrm{A}$, and cysteine proteinases [5-7]. Differences in the virulence of strains maintained in different culture conditions [8], like passage through liver hamster [9] and prolonged axenic culture [10], were also reported. These data suggest a modulation of gene expression during development of invasive amoebiasis and that this process is regulated by multiple and complex pathways. It is believed that not all genes involved in the invasive process are known. Therefore, the analysis of gene expression in different strains of E. histolytica and in different culture conditions is extremely important for a better understanding of the biology of this parasite since give us data to support the participation of new and already known factors on its virulence. In this context, the purpose of this study was to identify genes 
TABLE 1: Oligonucleotides used in the differential display reaction.

\begin{tabular}{ll}
\hline Oligo & Sequence \\
\hline AP1 & 5'ACAGGATTAATTAATACATTAGAAAAT3' \\
AP2 & 5'ACAGGACTTATTAATACACCTTGAAAAT3' \\
AP3 & 5' ACTGGTTTAATTAATACTTTAGAAAAT3' $^{\prime}$ \\
ERR1 & 5'CGCTCAAAATATCCACTTCTAC3' \\
RD5 & 5'ATCTGGTTGATCCTCCTGCCAGT3' \\
Kcal 1 & 5'GCGGCCGCTCAGGGGTTTTCCTTC3' \\
Kcal2 & 5'CTCGAGAAAAGAGTTGTTGGAGGATATAAC3' \\
GR & 5'CTCGAGAAAAGAGTTGTTGGAGGATATAAC3' \\
Edmt1 & 5'TATTATAATGGCTTTATTTTG3' \\
PF & 5'TTCAACTCTGTGAGATGAATGC3' \\
CARBOXI- & \\
U & 5'CAGAGTGACCCTGCCTGC3' \\
RB1.1 & 5'CAGGTGTGTGAGCATGGGC3' \\
\hline
\end{tabular}

differentially expressed in trophozoites of the same strain of E. histolytica under different virulence conditions.

\section{Materials and Methods}

2.1. Strain of Entamoeba histolytica. The strain ICB-CSP (CSP), previously identified as E. histolytica [10], was chosen because it was isolated from a patient with dysenteric colitis and also to present high capacity to cause lesions in tissues in experimental models. During maintenance on axenic culture, this strain had its virulence attenuated, losing their ability to cause lesions in tissues.

2.2. Virulence Activation. To activate the virulence, the trophozoites $\left(1 \times 10^{6}\right)$ were inoculated in the left lobe of the liver of hamsters (Mesocricetus auratus). After 24 hours, the animals were sacrificed and liver fragments were grown in culture medium for reisolation of trophozoites. This strain was renamed as reisolated CSP (CSP-R).

2.3. Reverse Transcription. Total RNA was extracted (Trizol Reagent, Life Technologies, USA) from trophozoites $\left(1 \times 10^{6}\right.$ cells of strains CSP in culture and CSP-R), isolated directly from hamsters liver. The RNA was resuspended in $0.01 \%$ DEPC water, quantified by spectrophotometry, and stored in a freezer at $-80^{\circ} \mathrm{C}$ until use. Three microliters of RNA treated with deoxyribonuclease I (Life Technologies, USA) was used for cDNA synthesis. The reaction contained $25 \mathrm{ng} / \mu \mathrm{L}$ oligo $(\mathrm{dT})_{12-18}, 500 \mu \mathrm{M}$ each dNTP, $75 \mathrm{mM} \mathrm{KCl}, 3 \mathrm{mM} \mathrm{MgCl}_{2}$, $10 \mathrm{mM}$ DTT, and 200 units of reverse transcriptase (SuperScript II RNase H-reverse transcriptase, Invitrogen, USA) in $50 \mathrm{mM}$ Tris- $\mathrm{HCl}$ buffer $(\mathrm{pH} \mathrm{8.3)}$ in a final volume of $10 \mu \mathrm{L}$. The reaction was carried out at $42^{\circ} \mathrm{C}$ for 50 minutes, as negative control samples were also prepared without addition of reverse transcriptase. Differences in expression levels between CSP and CSP-R were analyzed using the RNA differential display as previously described [11]. For PCR a single random primer was used (Table 1).

2.4. Polymerase Chain Reaction. PCR was carried out in $10 \mathrm{mM}$ Tris- $\mathrm{HCl} \mathrm{pH} 8.4$ buffer containing $50 \mathrm{mM} \mathrm{KCl}$, $1.5 \mathrm{mM} \mathrm{MgCl}_{2}, 0.1 \%$ Triton X-100, $200 \mu \mathrm{M}$ each dNTP, $2.6 \mu \mathrm{M}$ of random primers (Table 1), and 0.12 units of Taq DNA polymerase (Phoneutria, MG, Brazil) plus $1 \mu \mathrm{L}$ of cDNA sample in a final volume of $10 \mu \mathrm{L}$. Samples were submitted to two cycles of 2 minutes at $95^{\circ} \mathrm{C}, 1$ minute at $37^{\circ} \mathrm{C}$, and 2 minutes at $72^{\circ} \mathrm{C}$, followed by 29 cycles of 1 minute at $95^{\circ} \mathrm{C}, 1$ minute at specific temperature for each primer, and 2 minutes at $72^{\circ} \mathrm{C}$. The reaction product was loaded on nondenaturing $6 \%$ polyacrylamide gel $(16 \mathrm{~mm} \times 13 \mathrm{~mm} \times 1 \mathrm{~mm})$, in TAE buffer (Tris-acetate-EDTA), under an electric field of 100 volts. The gels were stained with silver nitrate [12]. Fragments of gel containing the bands with the differentially expressed genes were transferred to microfuge tubes in which were added $10 \mathrm{mM}$ Tris- $\mathrm{HCl} \mathrm{pH} 8.4$ buffer containing $50 \mathrm{mM} \mathrm{KCl}$, $1.5 \mathrm{mM} \mathrm{MgCl} 2,0.1 \%$ Triton X-100. This mixture was heated at $95^{\circ} \mathrm{C}$ for 20 minutes. The cDNAs extracted from the gel were used in a reamplification PCR using $10 \mathrm{mM}$ Tris- $\mathrm{HCl}$ $\mathrm{pH} 8.4$ buffer containing $50 \mathrm{mM} \mathrm{KCl}, 1.5 \mathrm{mM} \mathrm{MgCl}_{2}, 0.1 \%$ Triton X-100, $200 \mu \mathrm{M}$ each dNTP, $0.6 \mu \mathrm{M}$ of one primer, and 1.0 unit of Taq DNA polymerase (Phoneutria, MG, Brazil). The program used was similar to that described above excluding the initial cycle of annealing at $72^{\circ} \mathrm{C}$. The products were loaded on a $1 \%$ agarose gel stained with ethidium bromide $(0.5 \mu \mathrm{g} / \mathrm{mL})$ and purified from the gel using the GFX kit (Amersham Pharmacia Biotech Inc.) according to manufacturer's instructions. The purified cDNA was cloned into pGEM-T easy vector (Promega, Madison, WI, USA) and transformed into Escherichia coli, strain DH5 $\alpha$. Positive clones were selected using the system ampicillin/IPTG/X-Gal [13]. The size of cloned fragments was confirmed by PCR.

2.5. DNA Sequencing and Sequence Analysis. Recombinant plasmids were isolated using Wizard Plus SV kit minipreps (Promega, Madison, WI, USA) and submitted to sequencing reaction. The sequencing reaction was performed according to the method previously described [14]. Reaction products were subjected to the sequencer ABI PRISM 3130. Each clone was sequenced two times in both directions and the sequences were compared with those deposited at the National Center for Biotechnology Information (http://www.ncbi.nlm.nih.gov/BLAST) and Sanger Institute (http://www.sanger.ac.uk/cgi-blast/submitblast/e_histolytica) using the Basic Local Alignment Search Tool program [15].

2.6. Real-Time PCR. The Kit SYBR Green PCR Master Mix (Power SYBR Green PCR Master Mix, Applied Biosystems, Foster City, CA, USA) was used. The primers for all sequences were designed using Primer Express V2.0 program (Applied Biosystems, USA) to generate fragments between 70 and $190 \mathrm{bp}$. All primers were previously tested in conventional PCR using the plasmids containing the cloned fragment as a positive control. As internal control, the expression levels 
TABLE 2: Similarities of fragments more expressed on the virulent strain obtained in the blast.

\begin{tabular}{|c|c|c|c|c|}
\hline Fragment & Size/homology & Protein and access number & Identity & Score \\
\hline $\mathrm{BH} 2$ & $251 \mathrm{bp} / 1-249$ & $\begin{array}{l}\text { Hypothetical protein of Entamoeba histolytica } \\
\text { HM-1:IMSS XP_655762.1 }\end{array}$ & $100 \%$ & 166 \\
\hline BH4 & $474 \mathrm{bp} / 104-304$ & $\begin{array}{l}\text { Acid phosphatase of Entamoeba histolytica HM-1:IMSS } \\
\text { XM_644626.1 }\end{array}$ & $96 \%$ & 283 \\
\hline BH6.2 & $182 \mathrm{bp} / 47-113$ & $\begin{array}{l}\text { Hypothetical protein of Entamoeba histolytica } \\
\text { HM-1:IMSS XM_643628.1 }\end{array}$ & $90 \%$ & 87.9 \\
\hline BH6.4 & $187 \mathrm{bp} / 3-134$ & $\begin{array}{l}\text { Hypothetical protein of Entamoeba histolytica } \\
\text { HM-1:IMSS XM_652098.1 }\end{array}$ & $94 \%$ & 198 \\
\hline $\mathrm{BH} 7$ & $377 \mathrm{bp} / 3-374$ & $\begin{array}{l}\text { Calcium-gated potassium channel protein of } \\
\text { Entamoeba histolytica HM-1:IMSS XP_655083.1 }\end{array}$ & $97 \%$ & 203 \\
\hline BH10.19 & 833 bp/1-617 & $\begin{array}{l}\text { Hypothetical protein of Entamoeba histolytica } \\
\text { HM-1:IMSS XM_645643.1 }\end{array}$ & $98 \%$ & 402 \\
\hline BH10.22 & $414 \mathrm{bp} / 162-413$ & $\begin{array}{l}\text { Ras guanine nucleotide exchange factor of Entamoeba } \\
\text { histolytica HM1:IMSS XP_649781.1 }\end{array}$ & $95 \%$ & 177 \\
\hline BH11 & $180 \mathrm{bp} / 1-96$ & $\begin{array}{l}\text { Plasma membrane calcium-transporting ATPase of } \\
\text { Entamoeba histolytica HM-:IMSS XP_651287.2 }\end{array}$ & $100 \%$ & 68.2 \\
\hline BH17 & $223 \mathrm{bp} / 2-199$ & $\begin{array}{l}\text { Hypothetical protein of Entamoeba histolytica } \\
\text { HM-1:IMSS XP_656432.1 }\end{array}$ & $100 \%$ & 117 \\
\hline BH18.34 & $255 \mathrm{bp} / 3-254$ & $\begin{array}{l}\text { Hypothetical protein of Entamoeba histolytica } \\
\text { HM-1:IMSS XP_001914291.1 }\end{array}$ & $94 \%$ & 409 \\
\hline BH18.36 & $102 \mathrm{bp} / 3-101$ & $\begin{array}{l}\text { Cdc48 similar protein of Entamoeba histolytica gb } \\
\text { AAF74998.1 }\end{array}$ & $64 \%$ & 25.8 \\
\hline $\mathrm{BH} 23$ & $115 \mathrm{bp} / 1-115$ & $\begin{array}{l}\text { Small-conductance mechanosensitive ion channel of } \\
\text { Entamoeba histolytica HM-1:IMSS XM_650592.1 }\end{array}$ & $100 \%$ & 213 \\
\hline
\end{tabular}

of the actin gene was determined [16]. The reactions were performed in 96-well plates, in a final volume of $25 \mu \mathrm{L}$ containing Power SYBR Green PCR Master Mix (Applied Biosystems, USA), $0.45 \mu \mathrm{M}$ each primer, and $1 \mu \mathrm{L}$ of cDNA. Amplification conditions consisted of 40 cycles of $95^{\circ} \mathrm{C} / 15 \mathrm{~s}$, $60^{\circ} \mathrm{C} / 45 \mathrm{~s}$, and $72^{\circ} \mathrm{C} / 30 \mathrm{~s}$. Reactions were carried out in duplicate. The dissociation stage was added to the program for which the analysis of specific amplification could be made after completion of reactions. For relative quantification of amplification products the method $2^{-\Delta \Delta \mathrm{Ct}}$ was used [17].

\section{Results}

The CSP strain had its virulence activated after the second passage through hamster liver. The lesions produced belong to the class IV as previously defined [18]. Only two of the primers used (Kcal 2 and RB1.1) showed no differences in the amplification profiles between CSP and CSP-R. Figure 1 illustrates an example of the differential profile using ERR1 primer. 29 fragments with higher levels of expression specific to virulent culture, the CSP-R, with sizes ranging from 170 to $1150 \mathrm{bp}$ (BH1 to $\mathrm{BH} 29$ ) were identified. These were extracted from the polyacrylamide gel and used in a reamplification reaction with the same primers they generated. Eighteen fragments do not generate any product or produce more than one fragment, and therefore were discarded. Eleven fragments showed products of the expected size and were successfully cloned. At least three colonies of each fragment were subjected to PCR to confirm the size of the inserts. Those which showed the expected size were submitted to sequencing. For some plasmids more than one sequence was obtained indicating comigration of the fragments. From the original 11 fragments 13 different sequences were obtained. One sequence showed no similarity with any of the genes present in the database and therefore was excluded from the study. Primers were designed for the 12 sequences that showed similarity with any gene present in the NCBI database (Table 2). All 12 pairs of primers were tested in a conventional PCR using the plasmids containing cloned fragments, used as positive controls, and cDNA products obtained from cultures in different conditions. All fragments were amplified (data not shown). However, in the realtime PCR only, six fragments (BH2, BH4, BH10.19, BH17, $\mathrm{BH} 18.34$, and $\mathrm{BH} 18.36)$ were successfully amplified. The corresponding DNA sequences were analyzed for peptide sequence prediction by SignalP 3.0 Server program available on http://www.cbs.dtu.dk/services/. Only the sequence BH10.9 showed signal peptide prediction. The genes showed differential expression in the range of 12.1- to 339-fold more expressed in the virulent culture (CSP-R) compared to the nonvirulent culture (CSP) (Figure 2).

\section{Discussion}

It is well established that E. histolytica is a pathogenic organism in which its virulence varies according to environmental conditions [19]. Therefore, studies of the transcription profile 


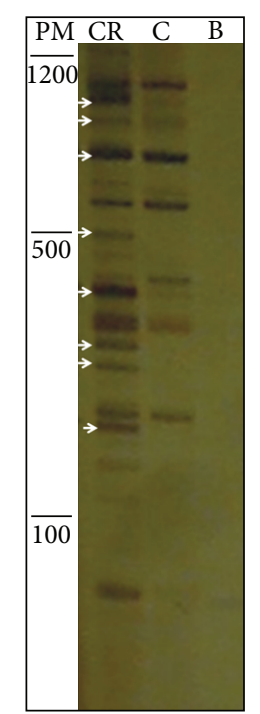

FIGURE 1: Differential display. Electrophoretic profile of differential display between virulent (CR) and nonvirulent (C) cultures of the strain CSP obtained in 6\% polyacrylamide gel. B is PCR negative control and PM is molecular mass standard in base pairs. The arrows show cDNA fragments of higher intensity in the virulent strain.

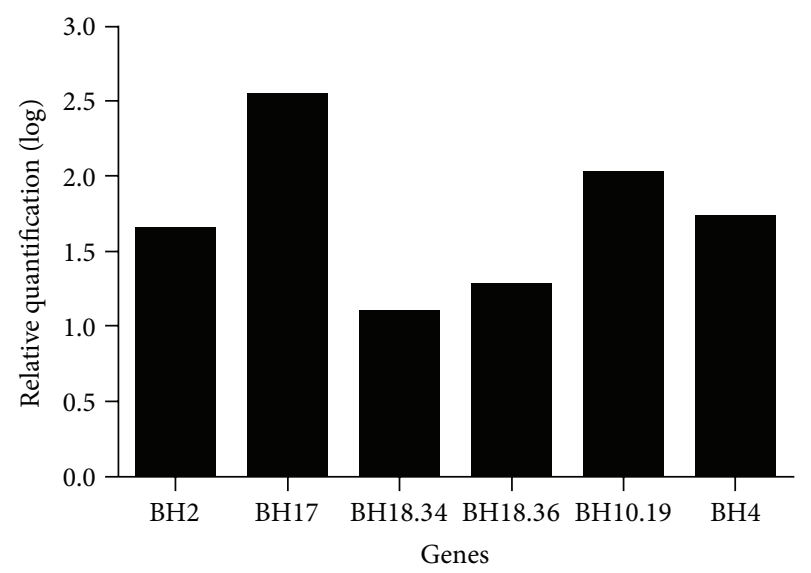

FIgURE 2: Comparison of quantitative RT-PCR data $\left(\log _{10}\right)$. Relative quantification of transcription in virulent versus nonvirulent $E$. histolytica cultures.

and changes in gene expression under different conditions are important for understanding the pathogenesis of these parasites and physiology including regulation of the life cycle stages of differentiation, development, and tissue invasion. In this context, the identification and characterization of differential gene expression may reveal important molecular markers in the events mentioned above. Different techniques have been used in studies to determine gene expression differences, such as differential display, subtractive hybridization of cDNA libraries, SAGE (serial analysis of gene expression), and cDNA microarrays [20-23].

Alterations in the expression pattern of molecules related to virulence may help to define invasiveness markers. Previous research has demonstrated differences in gene expression in trophozoites of $E$. histolytica presenting different virulence conditions [4-10, 16, 24-26]. However, they compared the pathogenic isolate HM-1:IMSS with the nonpathogenic Rahman or different cell lines of HM-1:IMSS. In this study we compared the gene expression of a Brazilian isolate of $E$. histolytica with high aggressiveness to experimental animals. This strain had its virulence attenuated by prolonged cultivation becoming unable to injury tissues. Its virulence was activated by inoculation into hamster liver. As the attenuated and activated isolates were taken from axenic culture, the differences found in the strain invading tissues can reveal new molecules involved in amoebic pathogenicity, in addition to confirmation of virulence genes found by other authors. For gene expression evaluation, the RNA differential display technique was used to be simple and allow the analyses of a large number of different transcripts from a small amount of RNA [20]. 29 segments that were more expressed in the virulent culture of E. histolytica (CSP-R) was selected. From 13 sequences that were successfully reamplified, 12 had their level of expression confirmed by semiquantitative RTPCR. However, only 6 had their expression level successfully analyzed by RT-qPCR.

SYBR green, a nonspecific fluorescence marker that binds to double-stranded DNA, was used in RT-qPCR. The SYBR contains in its structure a quaternary nitrogen positively charged, responsible for binding to DNA. We speculate that either the sequence composition or the amount and chemical characteristics of ions present in the samples could have interfered with the SYBR binding to the DNA. As a result, the fluorescence intensity would decrease, making detection of low expressed genes impractical. This may have occurred with the nonamplified fragments in RT-qPCR in this study.

One of the more expressed sequences of virulent culture is that of coding for acid phosphatase gene (fragment BH4). The acid phosphatase has been described in parasites such as Leishmania mexicana and Trypanosoma, being an essential enzyme for recycling membrane and endocytosis $[4,19]$, and may have a similar function in E. histolytica. Another gene more expressed in CSP- $\mathrm{R}$ is the Cdc48-like protein (fragment $\mathrm{BH} 18.36)$. This gene is also more expressed in E. histolytica stimulated by type I collagen and calcium ATPase activity presenting and participating in the processes of endo- and exocytosis [27]. E. histolytica is known for its high content of vesicles containing aggressive molecules such as lysozyme, pore-forming peptides, and proteinases.

Taking into account that it was evaluate transcripts of the same strain, capable (CSP-R) and unable (CSP) to cause lesions, the increased expression levels of genes encoding proteins such as acid phosphatase and EhCdc48-like, which are important elements in the regulatory mechanism of endocytosis, fusion of lysosomes, and recycling of membrane, suggest that these proteins may have important role in tissue invasion by the amoebae.

Four distinct sequences encoding hypothetical proteins (fragments $\mathrm{BH} 2, \mathrm{BH} 10.19, \mathrm{BH} 17$, and $\mathrm{BH} 18.34$ ) had also confirmed the differential expression, all of them more expressed in the virulent culture. One of these proteins had signal peptide, should be secreted, and may have a more direct action in the process of tissue damage in the host. 


\section{Conclusions}

Differences in gene expression presented here as well as those described by others may be related to adaptation of trophozoites due to difficulties during the colonization of the intestinal epithelium and liver tissue. Future studies of these genes may elucidate its actual role in amoebic tissue invasion, generating new pathways for diagnosis and treatment of amoebiasis.

\section{Conflict of Interests}

The authors declare that there is no conflict of interests regarding the publication of this paper.

\section{Acknowledgment}

This work was supported by CNPq (Conselho Nacional de Desenvolvimento Científico e Tecnológico), Brazil.

\section{References}

[1] WHO, "Amoebiasis," Weekly Epidemiological Record, vol. 72, pp. 97-99, 1997.

[2] L. A. Baxt and U. Singh, "New insights into Entamoeba histolytica pathogenesis," Current Opinion in Infectious Diseases, vol. 21, no. 5, pp. 489-494, 2008.

[3] C. D. Huston, "Parasite and host contributions to the pathogenesis of amebic colitis," Trends in Parasitology, vol. 20, no. 1, pp. 23-26, 2004.

[4] P. H. Davis, J. Schulze, and S. L. Stanley Jr., "Transcriptomic comparison of two Entamoeba histolytica strains with defined virulence phenotypes identifies new virulence factor candidates and key differences in the expression patterns of cysteine proteases, lectin light chains, and calmodulin," Molecular and Biochemical Parasitology, vol. 151, no. 1, pp. 118-128, 2007.

[5] R. Nickel, O. Claudia, T. Dandekar, and M. Leippe, "Poreforming peptides of Entamoeba dispar. Similarity and divergence to amoebapores in structure, expression and activity," European Journal of Biochemistry, vol. 265, no. 3, pp. 1002-1007, 1999.

[6] R. López-Vancell, I. Montfort, and R. Pérez-Tamayo, "Galactose-specific adhesin and cytotoxicity of Entamoeba histolytica," Parasitology Research, vol. 86, no. 3, pp. 226-231, 2000.

[7] C. He, G. P. Nora, E. L. Schneider et al., "A novel Entamoeba histolytica cysteine proteinase, EhCP4, is key for invasive amebiasis and a therapeutic target," Journal of Biological Chemistry, vol. 285, no. 24, pp. 18516-18527, 2010.

[8] A. Bahattacharya, M. T. Anand, J. Paul, N. Yadar, and S. Bahattacharya, "Molecular changes in Entamoeba histolytica in response to bacteria," Journal of Eukaryotic Microbiology, vol. 45, pp. 28S-33S, 1998.

[9] V. Tsutsumi, A. Ramirez-Rosales, H. Lanz-Mendoza et al., "Entamoeba histolytica: erythrophagocytosis, collagenolysis, and liver abscess production as virulence markers," Transactions of the Royal Society of Tropical Medicine and Hygiene, vol. 86, no. 2, pp. 170-172, 1992.

[10] M. A. Gomes, E. F. Silva, A. M. Macedo, A. R. Vago, and M. N. Melo, "LSSP-PCR for characterization of strains of Entamoeba histolytica isolated in Brazil," Parasitology, vol. 114, no. 6, pp. 517520, 1997.
[11] P. Liang and A. B. Pardee, "Differential display of eukaryotic messenger RNA by means of the polymerase chain reaction," Science, vol. 257, no. 5072, pp. 967-971, 1992.

[12] B. J. Bassam, G. Caetano-Anolles, and P. M. Gresshoff, "Fast and sensitive silver staining of DNA in polyacrylamide gels," Analytical Biochemistry, vol. 196, pp. 80-83, 1991.

[13] J. Sambrook, E. F. Fritisch, and T. Maniatis, Molecular Cloning: A Laboratory Manual, Cold Spring Harbor Laboratory Press, New York, 1989.

[14] F. Sanger, S. Nicklen, and A. R. Coulson, "DNA sequencing with chain-terminating inhibitors," Proceedings of the National Academy of Sciences of the United States of America, vol. 74, no. 12, pp. 5463-5467, 1977.

[15] S. F. Altschul, W. Gish, W. Miller, E. W. Myers, and D. J. Lipman, "Basic local alignment search tool," Journal of Molecular Biology, vol. 215, no. 3, pp. 403-410, 1990.

[16] R. C. MacFarlane and U. Singh, "Identification of differentially expressed genes in virulent and nonvirulent Entamoeba species: potential implications for amebic pathogenesis," Infection and Immunity, vol. 74, no. 1, pp. 340-351, 2006.

[17] K. J. Livak and T. D. Schmittgen, "Analysis of relative gene expression data using real-time quantitative PCR and the $2^{-\Delta \Delta C T}$ method," Methods, vol. 25, no. 4, pp. 402-408, 2001.

[18] L. S. Diamond, B. P. Phillips, and I. L. Bartgis, “The clawed jird (Meriones unguiculatus) as an experimental animal for the study of hepatic amebiasis," Archivos de Investigacion Medica, vol. 5, no. 2, pp. 465-470, 1974.

[19] I. Balderas-Renteria, J. F. García-Lázaro, P. Carranza-Rosales, L. H. Morales-Ramos, L. J. Galan-Wong, and L. E. MuñozEspinosa, "Transcriptional upregulation of genes related to virulence activation in Entamoeba histolytica," Archives of Medical Research, vol. 38, no. 4, pp. 372-379, 2007.

[20] P. Liang, "A decade of differential display," BioTechniques, vol. 33, no. 2, pp. 338-346, 2002.

[21] L. Diatchenko, S. Lukyanov, Y.-F. C. Lau, and P. D. Siebert, "Suppression subtractive hybridization: a versatile method for identifying differentially expressed genes," Methods in Enzymology, vol. 303, pp. 349-379, 1999.

[22] V. E. Velculescu, L. Zhang, B. Vogelstein, and K. W. Kinzler, "Serial analysis of gene expression," Science, vol. 270, no. 5235, pp. 484-487, 1995.

[23] S. Granjeaud, F. Bertucci, and B. R. Jordan, "Expression profiling: DNA arrays in many guises," Bioessays, vol. 21, pp. 781-790, 1999.

[24] I. Bruchhaus, T. Roeder, H. Lotter, M. Schwerdtfeger, and E. Tannich, "Differential gene expression in Entamoeba histolytica isolated from amoebic liver abscess," Molecular Microbiology, vol. 44, no. 4, pp. 1063-1072, 2002.

[25] M. Tillack, L. Biller, H. Irmer et al., "The Entamoeba histolytica genome: primary structure and expression of proteolytic enzymes," BMC Genomics, vol. 8, article 170, 2007.

[26] L. Biller, P. H. Davis, M. Tillack et al., "Differences in the transcriptome signatures of two genetically related Entamoeba histolytica cell lines derived from the same isolate with different pathogenic properties," BMC Genomics, vol. 11, no. 1, article 63, 2010.

[27] G. León-Avila, M. Hernández, M. Camacho-Nuez et al., “Entamoeba histolytica up-regulates the CDC48-like protein, an family member, during the activation of trophozoites with collagen type I and calcium," Molecular and Biochemical Parasitology, vol. 146, pp. 113-119, 2006. 

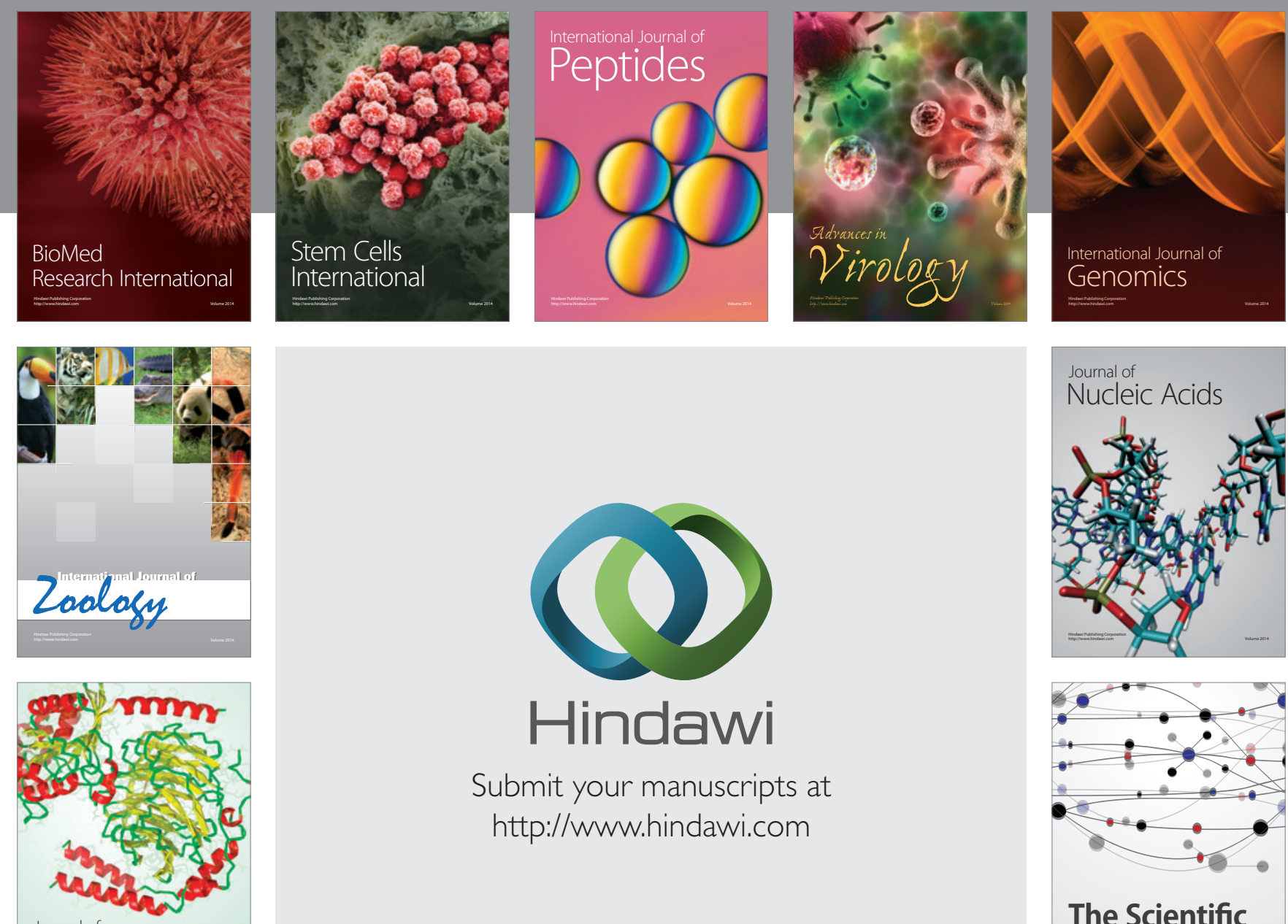

Submit your manuscripts at

http://www.hindawi.com

Journal of
Signal Transduction
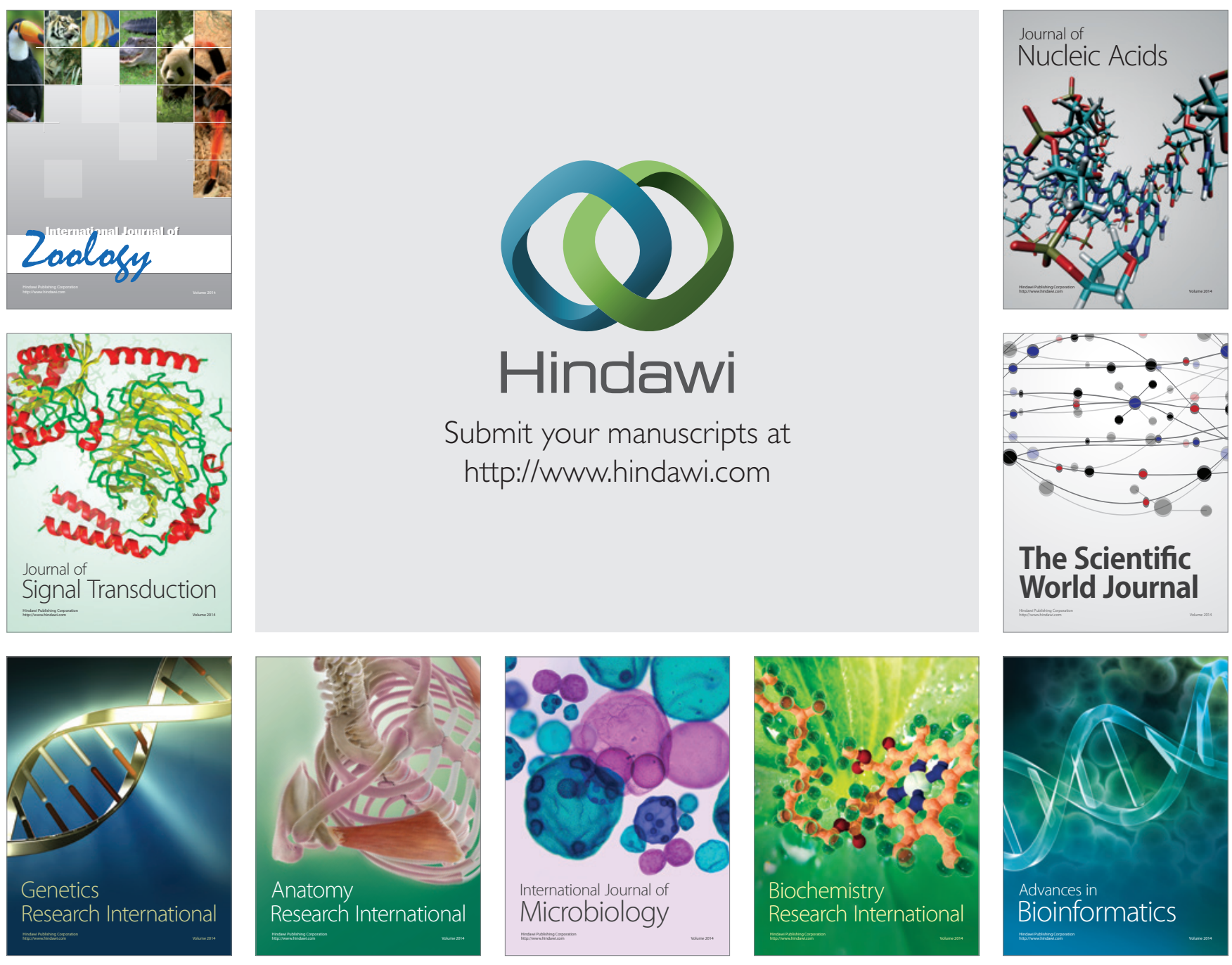

The Scientific World Journal
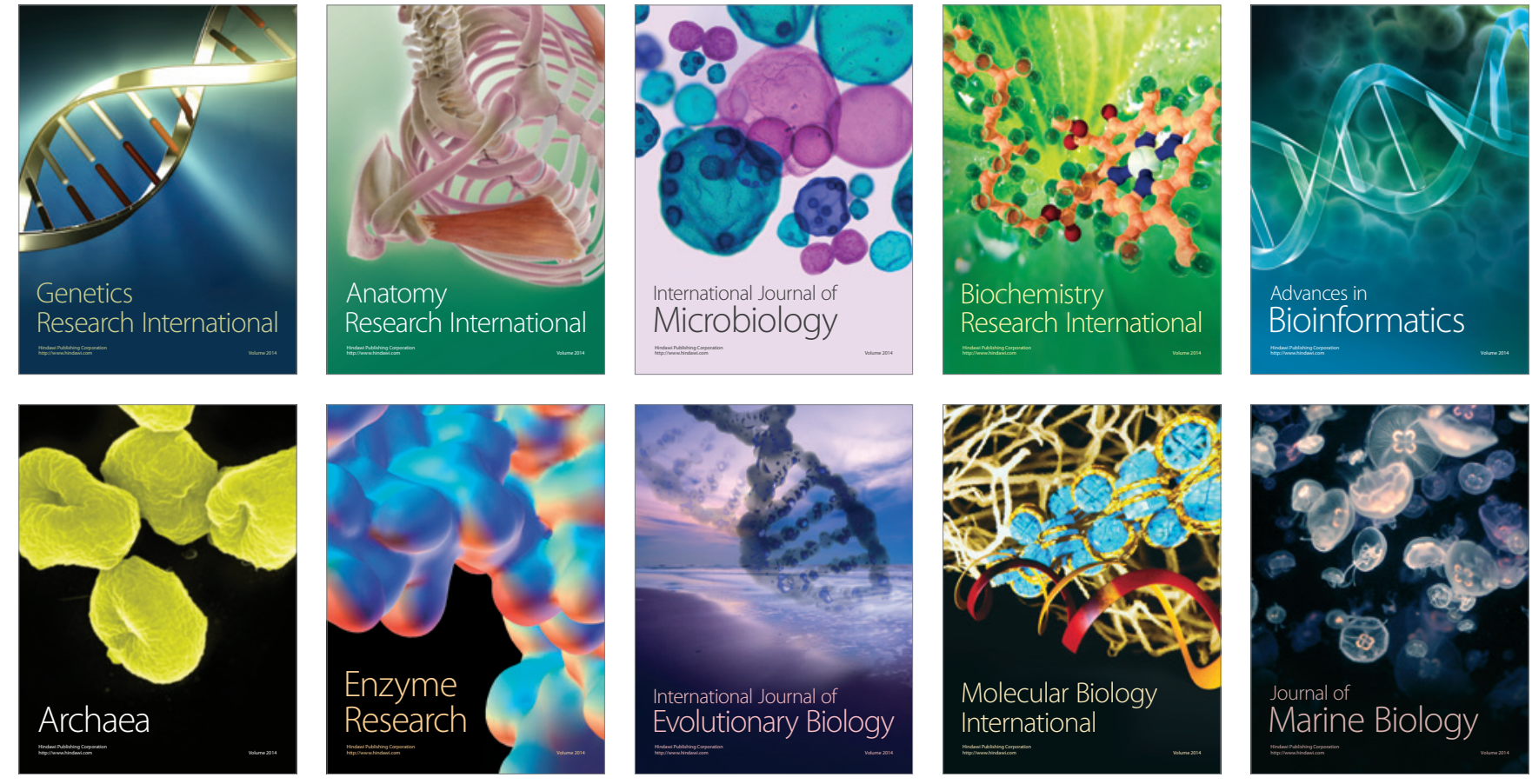